\title{
Quality of Nursing Care in Hospitalized Patients of the Carlos Lanfranco La Hoz Hospital, 2019
}

\author{
Amancio Izquierdo-Príncipe ${ }^{1}$, Jaqueline Garcia-Núñez ${ }^{1}$, Brian Meneses-Claudio $^{2, *}$, Hernan Solis-Matta $^{1}$, Lourdes Matta-Zamudio ${ }^{1}$ \\ ${ }^{1}$ Faculty of Health Sciences, Universidad de Ciencias y Humanidades, 15314, Lima-Perú \\ ${ }^{2}$ Image Processing Research Laboratory (INTI-Lab), Universidad de Ciencias y Humanidades, 15314, Lima-Perú
}

\begin{tabular}{l} 
A R T I C L E I N F O \\
\hline Article history: \\
Received: 03 August, 2020 \\
Accepted: 08 December, 2020 \\
Online: 16 December, 2020
\end{tabular}

Keywords:

Quality of care

Patient Satisfaction

Hospitalized Patients

Nursing Care

Hospital

\begin{abstract}
A B S T R A C T
Background: The quality of care of the nursing professional in relation to the hospitalized patient refers to the set of knowledge and attitudes that the nursing professional must provide quality care, preventing risks and improving patient satisfaction, for which its objective is to determine the quality of nursing care in hospitalized patients at the LanFranco la Hoz Hospital. Method: it is a quantitative, non-experimental, descriptive, and cross-sectional study with a study population of 143 patients in total hospitalized at the Carlos LanFranco la Hoz Hospital. Results: The results obtained in the quality of nursing care in hospitalized patients, it can be seeing that 86 patients representing $60.1 \%$, are moderately satisfied, followed by 36 patients that represent $25.2 \%$ are satisfied, 12 patients that represent $8.4 \%$ are dissatisfied, 7 patients that represent $4.9 \%$ are very satisfied and finally 2 patients that represent $1.4 \%$ are very dissatisfied. In the dimension, experience of the nurse in the care of hospitalized patients, it can be observed 69 patients that represents $48.3 \%$ are moderately satisfied with the experience of the nurse in the care and in the dimension satisfaction with nursing care in hospitalized patients, it can be see 93 patients that represents $65 \%$ are satisfied with the quality of care. Conclusions: It is concluded that the high demand for patients sustains a decrease in quality nursing care due to the scarcity of human resources in the hospital and it is recommended that the hospital have a permanent evaluation system of quality of care to meet the expectations of hospitalized patients.
\end{abstract}

\section{Introduction}

The World Health Organization (WHO) notes that 421 million people are hospitalized annually, these patients suffer approximately 42.7 million adverse events according to the most accurate evaluations and damage to patients during their hospital care are the cause of global mortality [1].

One of the factors of the quality of care is the perception that the hospitalized patient has during its hospital stay under care of hospital health personnel [2], since they fix their gaze on health personnel, easily judge and criticize the care provided, therefore, the position of the hospitalized patient will be evident when it comes to refusing care and advising that they should not be treated in that health facility [3].

Likewise, the care provided by the nurse towards patients has been perceived as deficient, because technology has influenced the nurse, where patient care is managed in a less humanized way, therefore the nurse-patient relationship loses every time trust [4].

*Corresponding Author: Brian Meneses-Claudio, Mr., +51 1950159924 \& bmeneses@uch.edu.pe

www.astesj.com

https://dx.doi.org/10.25046/aj0506159
Likewise, the relationship of the family members of the hospitalized patient and the nurse who cares is essential for comprehensive health care, the adverse effects generated by negative environments for not providing good information timely and understandable for the family are negative factors for hospitalized patients [5].

The length of stay of hospitalized patients in the hospital is an impact on the accessibility of new patients entering the hospitalization service for the first time, generating demand both in the emergency area and hospitalization in the health sector [6].

In [7], the authors presented a study carried out in Jordan, it indicates that in the health area a topic of quality and safety is needed, this contributes to all personnel being trained responsibly, providing quality care and safety. The presence and permanence in health services are considered as a fundamental factor to promote the safety of hospitalized patients.

In [8], the authors mentioned a study carried out in Colombia, it was possible to find a total quality of care reached in $62 \%$. The 
dimension with the highest quality was " monitoring and followup" (73.2\%) and the lowest was "anticipates" (56.1\%). 42\% of the patients said they had not been attended and did not recognize the nurse of the service.

In [9], the author described a study carried out in Russia, it refers that the perception, both of the health professional and the users, have a link in the human resource, which is ethical, the evaluations of hospitalized patients showed that are linked to the changeable, the concern of the hospital, and the obligation of public employees to provide quality care.

In [10], the authors presented a study carried out in Mexico, indicates that the quality of nursing professionals care towards patients highlighted 31 patients that represents $44.0 \%$ reported that the nursing staff managed their work tools (baumanometer, stethoscope, secretion aspirator, among others) as they expected; 22 patients that represents $31.0 \%$, better than they expected, and 32 patients that represents $30.0 \%$, as they did not expect.

The objective of the study is to determine the quality of nursing care in hospitalized patients of the Carlos Lanfranco la Hoz hospital, in which it will allow to observe the quality of care that nursing professionals have towards hospitalized patients. This study is important since it will give relevant and real data about how the nursing care is provided to patients hospitalized for a disease.

In the study, the Spanish-version quality of care data collection instrument (CUCACE) was applied by Alonso R. and the original version The Newcastle Satisfaction with Nursing Scales (NSNS) by Thomas in Scotland has been demonstrated its usefulness to assess the quality of nursing care.

The data collection was processed through the survey of hospitalized patients of the Carlos LanFranco la Hoz Hospital, the data to be entered was carried out in a data matrix that will be designed in the statistical program IBM SPSS Statistics Base 25.0, it was proceeded to its corresponding analysis, in which it will allow a better data processing to make statistical tables and graphs so that can be described and interpreted in results and discussions, respectively.

The following research work is structured as follows: In section II, the development of the hospitalized patient data collection process will be presented, as well as the guidelines to consider so that they are within the research work. In section III, the results will show the quality of care presented by nursing professionals according to the specified dimensions of the instrument in the measurement of the variable. In section IV, it will present the discussions of the research work, in section $\mathrm{V}$, the conclusions and in section VI the recommendations as well as the future work that is intended to be reached with the research work.

\section{Methodology}

In this part, the type and design of the research will be developed, as well as the population and the sample that will be carried out in the research work, the inclusion and exclusion criteria in detail and finally the technique and the instrument for collecting data.

\subsection{Research type and design}

The present study, due to its characteristics, the way of collecting data and measurement of the variables involved is a quantitative approach. Regarding the methodological design, it is a non-experimental, descriptive, cross-sectional study [11].

\subsection{Population}

The study worked with a total population of 143 hospitalized patients from the Carlos LanFranco la Hoz Hospital, which are distributed in 4 areas (Medicine, Surgery, Gynecology and Emergencies).

\subsection{Inclusion criteria}

- Adult patients with more than 2 days of hospitalization.

- Patients not receiving sedatives as treatment.

- Patients who have signed the informed consent.

\subsection{Exclusion criteria}

- Adult patients with less than 2 days of hospitalization.

- Patients with an altered state of consciousness, a language disorder, or a risk complication.

- Patient who has not signed the informed consent.

\subsection{Technique and instrument}

The data collection technique used in the research work was the survey, which important data will be obtained optimally and effectively. The survey will determine the quality of care in hospitalized patients using the (CUCACE) questionnaire, the Spanish version was validated by Alonso $\mathrm{R}$. and the original version is The Newcastle Satisfaction with Nursing Scales (NSNS), validated by Thomas in Scotland. The CUCACE questionnaire has three sections: The first is the experience with nursing care that it has 26 items, the second is the satisfaction with the nursing care that it has 19 items and the third is the sociodemographic variable such as: age, sex, educational level, days of stay in the service and some general questions [2].

Regarding statistical validity, this was obtained using the Kaiser-Meyer-Olkin sample adequacy tests and Bartlett's sphericity test. The results of the sphericity test are significant while the sample adequacy test obtained a value of 0,897 (KMO> $0.6)$ and the results of the sphericity test obtained a favorable value $\left(\mathrm{X}^{2} 3702,347\right.$; g.l. $\left.=990 ; \mathrm{p}=0,000\right)$. Likewise, Cronbach's alpha index obtained a value of $0.939(\alpha>0,6)$. All the above tests confirm an acceptable index of validity and reliability of the instrument.

This research work will consider the safety aspects of human research participants regarding to quality in hospitalized patients. The ethical behavior of deontological and moral health personnel. The bioethical principles: autonomy, justice, beneficence and non-maleficence, which constitute the basis for reasoning and orientation to their actions [12].

Medical ethics deals with the foundations that govern professional conduct in the practice of medicine, both in the doctor-patient and interprofessional relationships [13]. For this reason, the ethical authorization was carried out correctly when 
coordinating with the hospital authority and with the patient itself and its family to carry out the research work.

Bioethical principles are interpreted into fundamental values and rights of hospitalized patients [14]. In the present research work, the bioethical principles of beneficence, non-maleficence, justice, and autonomy were mainly taken.

\subsection{Place and Application of the Instrument}

The questionnaire to measure the quality of nursing care in hospitalized patients of the Carlos Lanfranco la Hoz hospital, Lima - Peru was carried out on a programming date with the hospital, the time used in each service was approximately 25 minutes, in each service a document was requested for the hospitalized patient to participate in the research work (according to the criteria of inclusion and exclusion), concluding with good satisfaction when collecting the questionnaires from hospitalized patients since they provided a lot of support to carry out the research work.

It is important to emphasize the presence of relatives of some hospitalized patients at the time of completing the questionnaire, since while the family member has the decision in turn that the hospitalized patient can participate in the research, in which they provided support to complete the questionnaires. At the same time, the presence of the nursing staff, since the questionnaire is based on patient care, which allows to observe if the nursing staff adequately performs the appropriate and/or necessary care for the patient.

\section{Results}

Below is a summary table of the surveys carried out following the guidelines corresponding to the research work:

Table 1: Sociodemographic Data of Quality of Nursing Care in Hospitalized Patients of the Carlos Lanfranco La Hoz Hospital, 2019 ( $\mathrm{N}=143$ )

\begin{tabular}{|l|l|l|}
\hline \multirow{2}{*}{$\begin{array}{l}\text { Participant } \\
\text { Information }\end{array}$} & \multicolumn{2}{|l|}{ Total } \\
\cline { 2 - 3 } Total & $\mathbf{N}$ & $\%$ \\
\hline Gender & 143 & 100 \\
\hline Female & 99 & 69,2 \\
\hline Male & 44 & 30,8 \\
\hline Marital Status & \multicolumn{2}{|l}{} \\
\hline Single & 37 & 25,9 \\
\hline Married & 21 & 14,7 \\
\hline Separated & 5 & 3,5 \\
\hline Cohabiting & 79 & 55,2 \\
\hline Widow & 1 & 0,7 \\
\hline Type of Family & \multicolumn{3}{|l}{} \\
\hline Nuclear & 100 & 50,2 \\
\hline
\end{tabular}

\begin{tabular}{|l|l|l|}
\hline Extended & 26 & 6,6 \\
\hline Expanded & 7 & 11,1 \\
\hline Single parent & 6 & 17,0 \\
\hline Reconstituted & 3 & 6,2 \\
\hline Single Person & 1 & 0,7 \\
\hline Study Degree & \multicolumn{2}{|l|}{} \\
\hline No study & 4 & 2,8 \\
\hline Incomplete primary & 12 & 8,4 \\
\hline Complete primary & 22 & 15,4 \\
\hline Incomplete secondary & 33 & 23,1 \\
\hline Complete secondary & 46 & 32,2 \\
\hline $\begin{array}{l}\text { Incomplete University } \\
\text { Studies }\end{array}$ & 7 & 4,9 \\
\hline $\begin{array}{l}\text { Complete University } \\
\text { Studies }\end{array}$ & 19 & 13,3 \\
\hline Occupation Condition & \multicolumn{2}{|l|}{} \\
\hline Stable & 14 & 9,8 \\
\hline Eventual & 51 & 28,7 \\
\hline Without occupation & 75 & 52,4 \\
\hline Retired & 2 & 1,4 \\
\hline Student & 5 & 3,5 \\
\hline Does not apply & 6 & 4,2 \\
\hline Days of hospitalization & 37,8 \\
\hline Three days & \multicolumn{2}{|l|}{} \\
\hline Four days & \multicolumn{2}{|l|}{} \\
\hline Five or more days & 38,6 \\
\hline
\end{tabular}

In Table 1 , it has the sociodemographic data of the study participants in total, there were 143 hospitalized patients from the Carlos Lanfranco La Hoz Hospital. Regarding gender, the female sex predominated with 99 patients representing $69.2 \%$, followed by the male with 44 patients representing $30.8 \%$.

Regarding the study degree, complete secondary school stands out with 46 patients representing $32.2 \%$, followed by incomplete secondary school with 33 patients representing $23.1 \%$, followed by complete primary school with 22 patients representing $15.4 \%$, followed by complete university studies with 19 patients representing $13.3 \%$, followed by incomplete primary school with 12 patients representing $8.4 \%$, followed by incomplete university studies with 7 patients representing $4.9 \%$ and finally no study with 4 patients representing $2.8 \%$. 
Regarding the days of hospitalization, four days predominate with 54 patients representing $37.8 \%$, followed by 51 days with 51 patients representing $35.5 \%$ and finally five or more days with 38 patients representing $26.6 \%$.

Below are figures that show the results about the total quality of nursing care in hospitalized patients and its dimensions according to the data based on the research instrument:

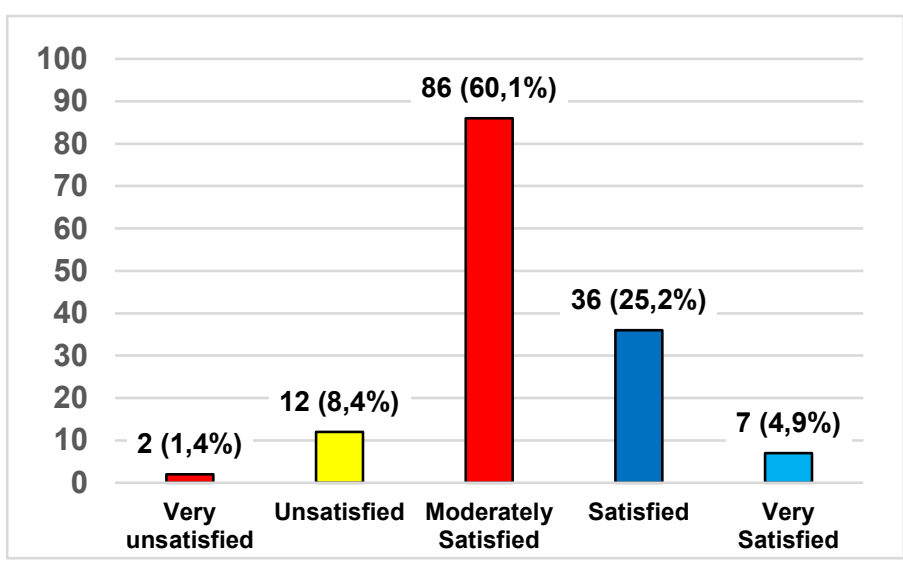

Figure 1: Quality of nursing care in hospitalized patients of the Carlos Lanfranco la Hoz Hospital, 2019 ( $\mathrm{N}=143)$

In Figure 1, the quality of nursing care in hospitalized patients of the Carlos Lanfranco la Hoz Hospital, it can see that 86 patients representing $60.1 \%$ are moderately satisfied, followed by 36 patients representing $25.2 \%$ are satisfied, 12 patients representing $8.4 \%$ are unsatisfied, 7 patients representing $4.9 \%$ are very satisfied and finally 2 patients representing $1.4 \%$ are very unsatisfied.

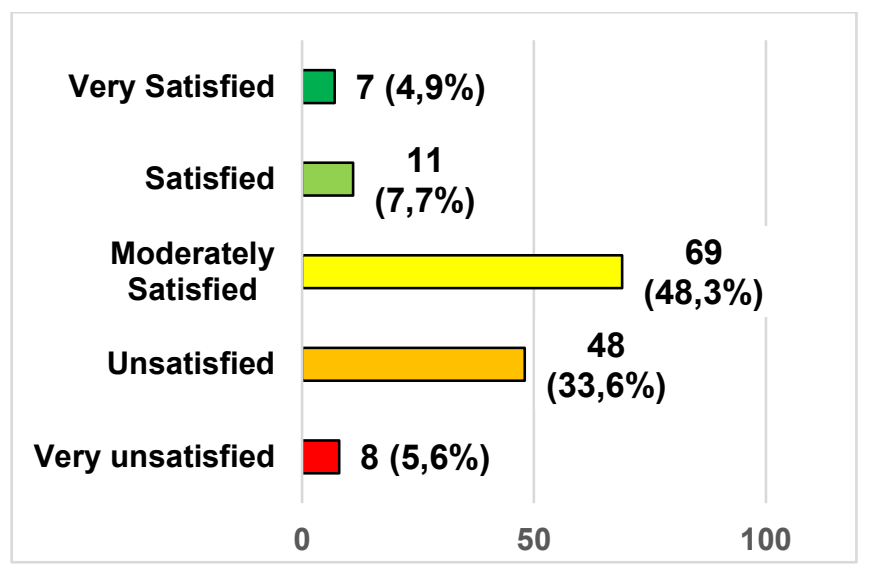

Figure 2: Quality of nursing care according to its dimension experience with nursing care, in inpatients in a public hospital in Lima Norte, $2019(\mathrm{~N}=143)$

In Figure 2, the quality of nursing care according to its dimension experience with nursing care, in hospitalized patients of the Carlos Lanfranco La Hoz hospital, it can see that 69 patients representing $48.3 \%$ are moderately satisfied, followed by 48 patients representing $33.6 \%$ are unsatisfied, 11 patients representing $7.7 \%$ are satisfied, 8 patients representing $5.6 \%$ are very unsatisfied and finally 7 patients representing $4.9 \%$ are very satisfied.

In Figure 3, the quality of nursing care according to its dimension of satisfaction with nursing care in hospitalized patients of the Carlos Lanfranco La Hoz hospital, it can see that 93 patients representing $65 \%$ are satisfied, followed by 32 patients representing the $22.4 \%$ are moderately satisfied, 13 patients that represent $9.1 \%$ are very satisfied, 5 patients that represent $3.5 \%$ are unsatisfied and finally 0 patients that represent $0 \%$ are very unsatisfied.

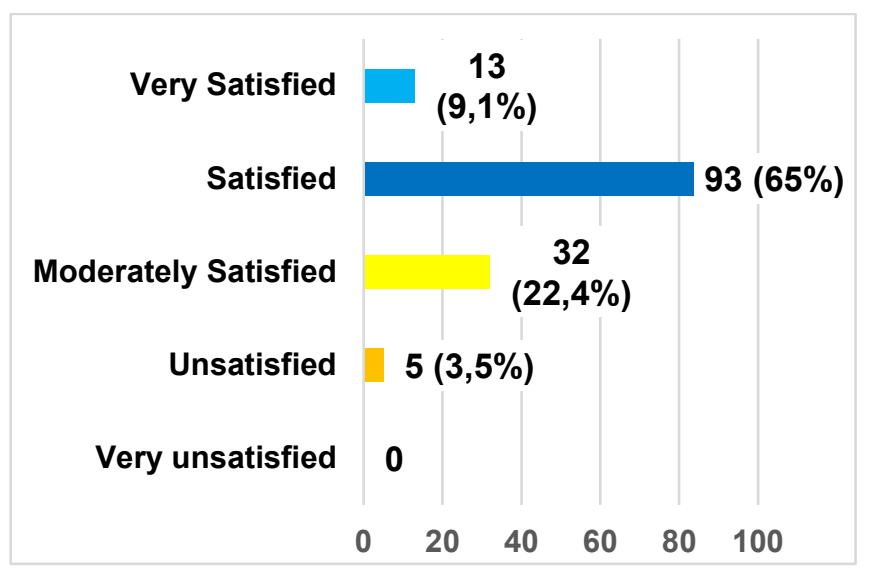

Figure 3. Quality of nursing care according to its dimension of satisfaction with nursing care, in hospitalized patients of the Carlos Lanfranco La Hoz hospital, $2019(\mathrm{~N}=143)$

Knowledge of these results is important since it will allow to show if the nursing professional is adequately caring for hospitalized patients, in the same way, it will allow to show if the hospitalized patient in turn collaborates with the staff of nursing for its care during its hospital stay.

\section{Discussion}

The quality of nursing care constitutes a fundamental tool that values nursing care in hospitalized patients in all aspects and dimensions that are involved in the health of the person and the population.

We agree with what was indicated by Kol E. et al., who affirm that the fundamental objective of measuring the quality of healthrelated nursing care is to assess the care provided in health services [15].

Regarding the quality of nursing care in hospitalized patients of a public hospital, $60.1 \%$ predominantly are moderately satisfied, followed by $25.2 \%$ are satisfied, $8.4 \%$ are unsatisfied, $4.9 \%$ are very satisfied and finally $1.4 \%$ are very unsatisfied. These findings can be explained due to the perception that hospitalized patients have, during their stay in the hospital, to the care of health personnel since they fix their gaze and easily judge, criticize the care provided.

Our findings coincide with those of Weldetsadik A. et al., they determine that the satisfaction of hospitalized patients symbolizes the care provided, if it meets their expectations. This magnitude is not necessarily directly related to the degree of scientifictechnical quality of the care provided [16].

The quality of nursing care is related to the dimension of experience with patient care mentioned by Amanda G. et al., they highlight the experience that hospitalized patients will have with the health professional, they are linked to the time that is provided during their hospital stay [17]. 
According to Becker R., he mentions that the wisdom of human resources is safe in medical practice, not only the care of patients is required and the attempt to provide quality care, the gift of expression is needed so that hospitalized patients can recover and reintegration into their family [18].

According to Allen A. et al., they point out the importance of technology as management support, but that it is not essential if there are trained or capable human resources. In many cases, a technological defect or the improper use of the equipment can lead to a failure in clinical analyzes that can lead to severe consequences for the life of hospitalized patients [19].

\section{Conclusions}

It is concluded that the use of a questionnaire CUCACE is important to evaluate the care received from hospitalized patients by the nursing professional, to evaluate the dimensions of experience and satisfaction with nursing care.

It is concluded that the high demand for patients sustains a decrease in quality nursing care due to the scarcity of human resources in the hospital.

It is concluded that the experience and work capacity of the nursing professional improves the quality and care of hospitalized patients.

It is concluded that it is essential to continue executing studies of this category, to analyze the outcome found and compare with current research, as well as facilitate its validity and reliability of CUCACE to measure the quality of nursing care in hospitalized patients.

\section{Recommendations}

It is recommended to carry out activities that promote communication with patients, since this interaction improves the nurse-patient relationship.

It is recommended that the hospital have a permanent quality of care evaluation system to meet the expectations of hospitalized patients.

\section{Conflicts of Interest}

The authors declare no conflict of interest.

\section{References}

[1] Organización Mundial de la Salud, 10 Datos Sobre Seguridad Del Paciente., OMS, 2018.

[2] C. Lenis, F. Manrique, "Calidad del cuidado de enfermería percibida por pacientes hospitalizados.," Aquichan, 15(3), 413-425, 2015, doi:10.5294/aqui.2015.15.3.9.

[3] P. Albujar, "Cuando el medico es el Paciente.," Fondo Editorial Comunicational, 32(3), 1-164, 2015, doi:10.35663/amp.2015.323.103.

[4] P. Ramírez, C. Müggenburg, "Relaciones personales entre la enfermera y el paciente.," Enfermería Universitaria, 12(3), 134-143, 2015, doi:10.1016/j.reu.2015.07.004.

[5] S. Geravandi, F. Soltani, M. Mohammadi, R. Alizadeh, A. Valipour, A. Hoseini, B. Rastegarimehr, A. Yari, A. Karimyan, A. Ghomeishi, "The effect of education on the nursing care quality of patients who are under mechanical ventilation in ICU ward.," Data in Brief, 16, 822-827, 2018, doi:10.1016/j.dib.2017.11.090.

[6] C. Wang, M. Zhao, T. Zeng, "Progress in applying patient experience in nursing quality improvement.," Chinese Nursing Research, 4(1), 1-4, 2017, doi:10.1016/j.cnre.2017.03.001.

[7] K. Al-Awamreh, M. Suliman, "Patients' satisfaction with the quality of nursing care in thalassemia units.," Applied Nursing Research, 47, 46-51, 2019, doi:10.1016/j.apnr.2019.05.007.

[8] E. Amed, G. Villareal, C. Alvis, "Calidad del cuidado de Enfermería brindado por profesionales en una ciudad colombiana. Revista Ciencia y Cuidado[revista en Internet] 2019 [acceso 01 de julio de 2019]; 16(2): 108119.," Revista Ciencia y Cuidado, 16(2), 108-119, 2019, doi:10.22463/17949831.1615.

[9] V. Sarkisova, "Quality of nursing care, availability and accessibility of treatment and prevention of communicable and chronic diseases.," International Journal of Nursing Sciences, 4(4), 350-351, 2017, doi:10.1016/j.ijnss.2017.10.016.

[10] M. Marín, C. Álvarez, J. Valenzuela, "Percepción de la atención de enfermería y satisfacción laboral en un Hospital de Seguridad Social.," RICSH Revista Iberoamericana de Las Ciencias Sociales y Humanísticas, 6(11), 287, 2017, doi:10.23913/ricsh.v6i11.119.

[11] C. Fernández, P. Baptista, Metodología de la Investigación. 6ta ed. México: Mc Graw-Hill/Interamericana., 2015.

[12] O. Vera, "Aspectos bioéticos en la atención de los pacientes de las unidades de cuidados intensivos.," Revista Medica La Paz, 21(1), 61-71, 2015.

[13] J. Martínez, C. Laucirica, E. Llanes, "La ética, la bioética y la investigación científica en salud, complementos de un único proceso.," Revista Médica Electrónica, 37(4), 310-312, 2018.

[14] L. Mora, "Los principios éticos y bioéticos aplicados a la calidad de la atención en enfermería.," Revista Cubana de Oftalmología, 28(2), 228-233, 2015.

[15] E. Kol, F. Arıkan, E. İlaslan, M. Akınci, M. Koçak, "A quality indicator for the evaluation of nursing care: determination of patient satisfaction and related factors at a university hospital in the Mediterranean Region in Turkey.," Collegian, 25(1), 51-56, 2018, doi:10.1016/j.colegn.2017.03.006.

[16] A. Weldetsadik, T. Gishu, T. Mekonnen, A. Mekonnen, L. Girma, T. Demas, "Quality of nursing care and nurses' working environment in Ethiopia: Nurses' and physicians' perception.," International Journal of Africa Nursing Sciences, 10, 131-135, 2019, doi:10.1016/j.ijans.2019.03.002.

[17] M. Trincado, E. Fernández, "Calidad en enfermería.," Rev Cubana Enfermer, 11(1), 1-5, 1995.

[18] R. Becker, "Recordando a Sir William Osler a 100 años de su fallecimiento: ¿qué podemos aprender de su legado?.," An Fac Med, 76(1), 71-6, 2015, doi:10.15381/anales.v76i1.11078.

[19] A. Allen, J. Robinson, M. Stewart, "Healthcare Quality: A Concept Analysis.," Nursing Forum, 52(4), 377-386, 2017, doi:10.1111/nuf.12207. 